\title{
DANÇAR COMO POLÍTICA DE EXISTÊNCIA ${ }^{1}$
}

\author{
DANCING AS A POLICY OF EXISTENCE
}

Nayara Lima Longo ${ }^{2}$

Resumo: Este trabalho pretende criar um campo de questões que ajudem a problematizar as interfaces entre processos de invenção de modos de existência e algumas práticas em dança. Entende-se que o corpo em dança pode funcionar como dispositivo catalisador de políticas de invenção de modos de vida outros. De modo que o dançar é tomado como prática aberta a uma multiplicidade de conjugações e derivações possíveis, onde o que interessa é a inauguração de relações outras para consigo e para com mundos.

Palavras-chave: Dança; corpo; política.

Abstract: This work intends to create a field of questions that help to problematize the interfaces between processes of invention of existence modes and some practices in dance. It is understood that the dancing body can act as a catalyst device for policies to invent other ways of life. It's considered that dancing is taken as a practice open to a multiplicity of possible conjugations and derivations, where what matters is the inauguration of other relationships with oneself and with worlds.

Keywords: Dance; body; policy.

Mas por que não podemos fazer da nossa vida uma obra de arte? Acordar pelas manhãs abertas desaprendendo princípios a fim de, quiçá, apalpar as intimidades do mundo.

A maior riqueza do homem é sua incompletude.

Nesse ponto sou abastado

Palavras que me aceitam como sou- eu não aceito.

Não aguento ser apenas um sujeito que abre

portas, que puxa válvulas, que olha o relógio, que

compra pão às 6 horas da tarde, que vai lá fora,

que aponta lápis, que vê a uva etc. etc.

Perdoai.

Mas eu preciso ser Outros.

Eu preciso renovar o homem usando borboletas.

(Barros, 2009)

Penso que o alinhavo das indagações que atravessam este trabalho seja sobre modos de criação e sustentação de territórios corporais sensíveis que deem conta de produzir-se em agenciamento com as singularidades éticas e políticas disparadas em cada acontecimento. Ou, talvez, em outras palavras, trata-se da abertura de lapsos de ressonâncias, fragmentos de passagens que permitam tomar o corpo em seu lócus sensível a fim de angariar ferramentas na constituição de corpos atentos a si, ética, sensível e politicamente. Trata-se da possibilidade de acolher e dar passagem a um plano disruptivo da experiência de si para com o corpo próprio,

\footnotetext{
${ }^{1}$ O presente trabalho foi realizado com apoio da Coordenação de Aperfeiçoamento de Pessoal de Nível Superior - Brasil (CAPES) Código 001.

${ }^{2}$ Universidade Federal da Bahia, BA, Brasil.
} 
dimensão esta geralmente ofuscada pelos planos de representação e esquematização de gestos cotidianos, bem como para os sentidos a eles já atribuídos como que de antemão.

Que acontecimentos podem ser agenciados a cada vez a partir desta dimensão sensível da experiência de si? Como delinear territórios corporais que possam funcionar como causa ativa na afirmação das alegrias e potências da existência? Como cultivar uma região outra de afetação, de modo a dar consistência gestual a uma pluralidade de multiplicidades intensivas que excedem formas visíveis? Corpo atualizando-se a cada vez, em um sempre excesso em relação ao que o produz e produziu, descascando, rompendo em contínuos partos de si.

Nos rastros da bailarina, educadora e coreógrafa brasileira Angel Vianna (Miller 2007; Ramos 2007; Longo, 2015), procurar- se- á aqui tratar o gesto do dançar não como conjunto de virtuoses e técnicas exclusivas de corpos bailarinos especialistas, mas sim, como potência comum de todos os corpos em seus movimentos de singularização. Utilizar- se- á como intercessor na composição da escrita fragmentos de um diário de bordo ${ }^{3}$ construído durante algumas experimentações em dança, principalmente a partir de práticas vividas junto a Faculdade de Dança Angel Vianna, durante realização de curso de especialização em Conscientização do Movimento e Jogos Corporais.

Interessam, pois, práticas, modos de tecimento na relação de si para consigo, que estejam operando na produção da vida como potência de passagens soberanas e afirmativas. Modos de fazer que possam disparar movimentos de intensificação e criação de si por si mesma. Tenta-se saltar no vazio da linguagem, de modo a dar passagem ao indizível, forças que se atravessam em contínuo movimento de escape, fazendo saltitar acontecimentos- corpo, mínimos gestos, silêncios. Como forjar artesanias da existência que, como pólen, atraiam a passagem em nós de seres saltitantes e coloridos? Mais do que respostas definitivas, este trabalho pretende se construir como um conjunto de problematizações inconclusas e contingentes.

Escrita da habitação de paradoxos. Palavras como operadoras de sensações e disparadoras de fluxos de corpos e pensamentos. Ferramentas que dizem de frequências possíveis, só validadas a cada vez na singularidade de cada experiência.

Alongar braços, cabeça, respiração que muda, olho que gira, chia, baque acelerado no coração, pernas, músculos das pernas, parte anterior, rigidez amolecida do pescoço. Escrevese, dança-se ao léu, acaso que brota de corpos e meios. Fabricar corpo é construção diária, atenta. É perceber e perceber-se sempre, a cada vez de um jeito novo. Como dar e ser passagem? Entregar, ceder, escutar, apalpar, tocar. Abrir um corpo pulsante, vibrátil, criar circuitos de conexões sanguíneas, hormonais, ósseas, plasmáticas, espaciais, políticas, sociais, cósmicas. Membrana que toca a superfície do mundo, porosa e repelente, aderir, compor, repelir, afastar. Um sempre suspenso e renovado estranhamento de si para consigo, para com as palavras e coisas do mundo (Diário de bordo, 2015/2021)

\footnotetext{
${ }^{3}$ Ferramenta do âmbito da análise institucional, que permite acompanhar os processos do pesquisar, evidenciando o "fora texto". Nas palavras de Lourau (1993, p. 37) o fora texto pode ser tomado como "escrita quase obscena, violadora da neutralidade". O que se tenta evidenciar é o quanto esta neutralidade é impossível, uma vez que, de um modo ou de outro, sempre se está imersa naquilo do que se fala. Para indicar os trechos do diário de bordo utilizaremos neste artigo outra fonte de escrita.
} 


\section{Consciência do corpo e dança}

José Gil (2004, p. 1) ao inquirir como o trabalho sobre o corpo influencia o espírito, afirma não ser o humano uma unidade psicofísica, em que o elemento físico se ligaria harmoniosamente ao somático para assim constituírem um ser uno. De acordo com ele, o ser seria um ser do inconsciente e da consciência, sendo esta - a consciência- considerada como elemento paradoxal: sempre em estado de estreita imbricação com o corpo, ela atravessaria situações de maior intimidade, mistura, osmose com o corpo; mas também estados de ruptura, afastamento e abandono do corpo ${ }^{4}$. Assim, ao conceituar a noção de consciência do corpo, o filósofo português (Gil, 2004) propõe que esta seja considerada como o avesso de certa intencionalidade tradicionalmente associada a noção de consciência.

Consciência do corpo então como uma espécie de impregnação da consciência pelo corpo. Tome-se a este respeito a experiência de certos estados em dança, experiência bailarina, em que torna- se possível sentir a energia fluindo através dos membros enquanto se percebe os movimentos da consciência acompanhando-os. É como se a consciência funcionasse como um meio ou uma atmosfera suscetível de ser envolvida, invadida, capturada, tomada, por texturas finíssimas que a obscurecem e que vem dos movimentos do corpo (Gil, 2004). Consciência que caminha pelo interior do corpo, construindo mapas deste espaço interno, como que em uma espécie de topografia de trajetos e lugares de energia (Gil, 2005, p. 100).

A consciência pode viajar no interior do corpo. É um fato análogo ao de dirigir o olhar, no mundo exterior. Há também uma consciência análoga à visão periférica, que é a consciência de corpo inteiro, mantendo-se de olhos abertos (Steve Paxon apud Gil, 2005, p. 99).

A noção de impregnação da consciência pelo corpo acaba por desmontar a concepção cartesiana que toma corpo e consciência como duas substâncias ou elementos opostos, caracterizada por um corpo situado no espaço e uma consciência incorporal (Gil, 2004). Invertendo tal proposição, ter-se-ia corpo e consciência como expressões de uma outra instância, em uma espécie de ontologia (Gil, 2004). Ao discorrer sobre o dançar Gil (2004) coloca que:

a impregnação do pensamento pelos movimentos do corpo opera num espaço virtual em que se actualizam ao mesmo tempo os movimentos corporais e os movimentos do pensamento. (...) [quando] a consciência se deixa invadir pelos movimentos do corpo, os dois elementos convergem, transformando-se, para o espaço único em que a osmose se produzirá: é no mesmo processo de actualização do movimento virtual em movimento do corpo no espaço e em movimento no pensamento, que ocorre a impregnação da consciência pelo corpo. É assim que não só a consciência devém corpo de consciência- em que os movimentos da consciência sabem de seu espaço tão imediatamente como o corpo sabe de seus gestos (practognósias) - mas o próprio corpo se torna consciência, capaz de captar os mais ínfimos, invisíveis e inconscientes movimentos dos outros corpos. Movimentos das forças e de pequenas percepções.

Fazer passar a consciência do corpo para o primeiro plano da consciência refere-se, pois, a uma mudança de escala, em que se dá pregnância ao que constitui uma espécie de regime subjacente a todo estado de consciência (Gil, 2004). Os movimentos corporais estão sempre presentes, mesmo

\footnotetext{
${ }^{4}$ Ainda que mesmo nestes casos um fio residual, muitas vezes inconsciente, faz com que ainda a consciência se reconheça como pertencente àquele corpo e não a outro (Gil, 2004).
} 
na consciência intencional ou habitual, ainda que ofuscados pela predominância de certa reflexionalidade e intencionalidade. Assim que "não há consciência sem que os movimentos corporais intervenham nos movimentos da consciência"; não há consciência sem consciência do corpo (Gil, 2004). O coreógrafo americano Steve Paxon (apud Gil, 2004) afirma que a consciência (intencional) que se tem dos movimentos corporais está cheia de buracos (gaps), uma vez que estes movimentos são demasiadamente rápidos para que a consciência clara os capte, ainda que para a consciência que a consciência tem de si, não haja buracos, mas sim uma continuidade sem interrupção, espécie de corrente de consciência sempre (ou quase sempre) preenchida por percepções, imagens, sensações, impressões, pensamentos e afins. Uma mudança de escala nesta corrente, entretanto, revelaria uma descontinuidade lacunar, espécie de duração esburacada. A consciência intencional é tomada, portanto, como intervalar sendo que em seus intervalos sucedemse movimentos do corpo tão ligeiros que passam desapercebidos (Gil, 2004).

Direcionar gentilmente a atenção ao modo como se está deitada, ao modo como se está de pé, são práticas corporais que mesmo em sua imobilidade e simplicidade aparentes, dizem de atravessamentos de forças fervilhantes, corpos que nunca param de devir formas e intensidades de si próprios e de mundos. Pequenas e quase imperceptíveis danças. Deduz-se daí a importância de políticas de existência que considerem estas dimensões da experiência de si, incorporando modos de acesso e expressão destas fagulhas corporais. Trata-se de aliar-se a dispositivos em dança que permitam dar espaço, passagem e expressão as pequenas percepções, acolhendo neste movimento a consciência como lugar de recepção de forças do mundo graças ao corpo (Gil, 2004).

Celebrar as horas em que o corpo se entrega ao chão, aliviando as forças da gravidade. Tempos em que o corpo se percebe, e percebe que pode inventar. Inventar gestos, caminhos no ar. Parar e sentir fluxos e pulsações. Conexão com células, sangue, ossos, tecidos, pele, espaço, vibrações do espaço. (Diário de bordo, 2015/2021).

\section{Criação de modos de existência}

Remansos de si ativando ventanias internas, que desdobram e multiplicam ventanias de mundo. Experiência em que cada gesto dançado abre no corpo a dimensão do infinito (Gil, 2004, p. 51). A disrupção não se faz no sentido de uma descoberta de si, nem de um enquadramento na representação de certas imagens corporais, mas na exploração de vazios, gaguejos, intervalos de si para consigo. Um fazer afetando outro, fundando um corpo que é causa ativa de si mesmo, rede de feixes porosos e interligados entre si e com o mundo. Simultaneamente articulam-se superfície e profundidade, expressando movimentos que exigem a atenção a um dentro que se desdobra em direção a um Fora ${ }^{5}$, que se desdobra em direção a um dentro.

A noção de Dobra, trazida por Deleuze (1988), talvez auxilie nesta problematização, na medida em que permite pensar o dentro como um interior do exterior. A partir desta noção abrese um campo de relação de si para consigo mesma imediatamente coextensivo a um fora, plano das multiplicidades, da pluralidade de forças que constituem relações no mundo. O dentro é tomado como um duplo do lado de fora, duplo que simultaneamente se desdobra para fora, em um movimento incessante. Como coloca Deleuze (1988, p. 105):

\footnotetext{
5 “ (...) apenas se estivermos abertos ao Fora e as entre-forças que o constituem, estaremos disponíveis para um a mais de força, isto é para uma nova qualidade da força” (Pelbart, 1989, p. 122).
} 
(...) não é o desdobramento do Um, é uma reduplicação do Outro. Não é uma reprodução do Mesmo, é uma repetição do Diferente. Não é a emanação de um EU, é a instauração da imanência de um sempre-outro ou de um Não-eu.

De maneira que embora uma relação consigo mesma seja atravessada por estratégias de captura imersas em dispositivos de poder hegemônicos, ela nunca é totalmente redutível a estes. Afirmar certa extemporaneidade, frente a experiência de um tempo compulsoriamente comprimido e acelerado pelas bolhas de produção e consumo neoliberais, em que a experiência do corpo é capitalizada em sua funcionalidade, engolindo neste movimento, múltiplos mundos ainda por nascer. $\mathrm{O}$ conceito de dobra permite o acesso a uma potência subversiva imanente na relação de si para consigo, na medida em que consiste na possibilidade de uma força afetar a si mesma ao mesmo tempo em que é afetada por outras forças. A vida pode sempre escapar, engendrando linhas de criação e afirmação de si e de mundos. Trata-se de convocar aqui, portanto, a urgência da necessidade de criação de modos de existência outros.

Desaprender a engolir as asperezas. Desaprender a sufocar o movimento do coração. Matar aqueles olhos chatos que te olham. Desaprender a performance do existir. Desaprender. Se ralar na aspereza crua e doce de ser um corpo em transição. Escutar o barulhinho dos próprios silêncios. Escutar o silêncio do/no mundo. Desaprender a julgar. Ouvir o outro, o mais chato, com uma inocência ativa, seletiva. Cada movimento tenso de si. Um pescoço que enverga. Uma mão que não abaixa. Uma corrente do coração saltando em direção as falanges da mão sorrateiramente alinhavando sentidos, segurando o tempo em memórias de antanhos. A cada vez a suavidade incisiva do toque das almofadinhas dos dedos conhecendo, inventando percursos outros no já vivido. Construção de conexões, elos, elãs, que não são da ordem da vontade, mas sim da ordem do acontecimento, verticalidade da coluna vertebral, solidez porosa e sustentada de fêmures, tíbias, rádios e ulnas. O bambu, objeto externo, que te lembra de ti, dureza e aconchego vertical, vertebral mobilidade. A bolinha de tênis que rolando pelo corpo desenrola, descola fluidos e intensidades ali grudadas talvez há eternidades. A cada rolar desalinhavos, fluxos de si liberados ativamente, abertura a lugares desconhecidos e novos na experiência. São cavalgares nômades o que se tece. 0 inusitado da experiência presente. Momentos que dedilham experientes o que não se sabe de si, o que não se sabe do entorno, o que não se sabe do tempo. Em cada pedacinhopartícula, a unidade se faz pela multiplicidade, espalhamento intensivo de ressonâncias dispares, ímpares. Dissolução que não é um perder-se. Ou que talvez, sim, se trate de um perder-se ativo, sustentado em um si mesmo que corajosa, artesanal e delicadamente dilui as resistências, padecendo a experiência do instante.

Não se trata mais de ser vista. Não se trata mais do olhar do outro. Nem um olhar que procura falhas. $\mathrm{O}$ olhar do administrador competente que procura culpas e sobrecarrega escápulas e esterno. Mas aprende-se aqui uma experiência estranha. Um olhar que acolhe. Que observa, entre curiosidade e espanto e gentileza, desdobramentos de si mesma. Não apenas um olhar complacente, mas uma complacência ativa, paciente, que sorrateiramente espera de esguelha a fim de habitar quem sabe este espaço as vezes brando, as vezes inóspito e cheio de espinhos, entre si e si mesma. Espaço da crueldade, como talvez dissesse Artaud, espaço da pulsante carne viva, osso vivo, veias e artérias e músculos, o ar e suas passagens, ritmos, circulações, esperas, o que nunca para, cabelo que embranquece. Acolher pequenas percepções. Tornar-se com. Dar espaço ao impensado. Surpreender-se com. O corpo já não 
submetido a um agente. Passagens que acontecem nas sutilezas da percepção de si, e deste si em relação com as outras pessoas e o espaço. Que corpo dança? "Eu não dançava. O que fazia era outra coisa: eu apagava o tempo e o peso, como cobra que se despe da velha pele" (Couto, 2012, p. 184-185). (Diário de Bordo 2015 / 2021).

\section{Dançar como política de existência}

A diferença entre agir e fazer, tal como pontuada por Deligny, (apud Pelbart, 2013) pode ser interessante nesta problematização. Para ele, o fazer coloca em jogo gestos que se direcionam a uma finalidade, um objetivo, fazer para. Escovar os dentes para que fiquem limpos. Pentear os cabelos para sair bem na selfie. Quanto ao agir, se trataria do sem finalidade, do gratuito, da passagem de forças que não se formatam pela linguagem e nem por uma ordenação a priori. Acredito que certas práticas em dança, especialmente as que vivi com a Metodologia de trabalho de Angel Vianna, foquem justamente neste processo do agir, plano de passagem e encontro de forças ainda não humanizadas ou psicologizadas. Aberturas catalisadas por singulares práticas corporais, onde friccionam-se e pluralizam-se universos quando da criação de si por si mesma. Emergência de corpos que se abrem a passagens e distribuições de intensidades, conexões que supõem agenciamentos, circuitos e conjunções. Jogo do corpo em dança, artesania de si para consigo compondo porosidades e modos de expressão em meio a atravessamentos inéditos e impessoais.

Em um estado de fluência intensiva, momento em que explodem sentidos de algum modo retidos num arco intencional familiar, os órgãos são intensificados de tal modo que se tornam, nesse entretempo aiônico, instante de eternidade, independentes da "forma organismo" (Orlandi, 2004). O que Deleuze e Guattari, inspirados em Artaud, chamam como corpo sem órgãos:

[O corpo sem órgãos] é um corpo intenso, intensivo. Percorrido de uma onda que traça no corpo os níveis ou os limites segundo variações de sua amplitude. O corpo não tem, portanto, órgãos, mas limites ou níveis. (...) O corpo é inteiramente vivo, e portanto não orgânico. (...) o corpo sem órgãos é carne e nervo; uma onda o percorre lhe traçando níveis; a sensação é como o reencontro da onda com Forças que agem sobre o corpo, "atletismo afetivo", grito-sopro (...). (Deleuze, 1981, p. 26).

Invasão dos poros da consciência vígil pelas pequenas percepções, cacos intensivos de si articulando-se como vetores de movimento; ativação de uma política de si, de encontros, de tecimentos de existências e mundos outros. Dançar como criação de políticas do existir.

\section{Referências}

BARROS, Manoel. Retrato do artista quando coisa. Rio de Janeiro: Record, 2009.

COUTO, Mia. A confissão da leoa. São Paulo: Companhia das Letras, 2012.

DELEUZE, Gilles. Foucault. São Paulo: Ed. Brasiliense, 1988.

DELEUZE, Gilles. Francis Bacon: Logique de La Sensation. Tradução de Silio Ferraz e Annita Costa Malufe. Paris: auxéditions de La différence, 1981.

GIL, José. Abrir o corpo. In: FONSECA. T.; ENGELMAN S. (Org.). Corpo, arte e clínica. Porto Alegre: UFRGS Editora, 2004. 
GIL, José. Movimento total: O corpo e a dança. São Paulo: Iluminuras, 2005.

LOURAU, Rene. Análise Institucional e práticas de pesquisa. Rio de Janeiro: Editora UERJ, 1993.

LONGO, L. Nayara. Artesanias do existir: Corpo e experimentação na Metodologia Angel Vianna. Monografia (Especialização em Conscientização do Movimento e Jogos Corporais). Rio de Janeiro, 2015.

MILLER, Jussara. A escuta do corpo: Sistematização da Técnica Klauss Vianna. São Paulo: Editora Summus, 2007.

PELBART, P. P. Da clausura do fora ao fora da clausura: loucura e desrazão. São Paulo: Ed. Brasiliense, 1989.

PELBART, P. Peter. O avesso do niilismo: Cartografias do Esgotamento. São Paulo: n-1 edições, 2013.

RAMOS, Enamar. Angel Vianna: A pedagoga do corpo. São Paulo: Editora Summus, 2007.

ORLANDI, Luiz. B. L. Corporeidades em minidesfile. In: FONSECA T.; ENGELMAN S. (Org.). Corpo, arte e clínica. Porto Alegre: UFRGS Editora, 2004.

\section{Sobre a autora}

Nayara Lima Longo é graduada em Psicologia (Universidade Estadual Paulista), especialista em Conscientização do Movimento e Jogos Corporais - Metodologia Angel Vianna (Faculdade Angel Vianna), especialista em Estudos Contemporâneos em Dança (Universidade Federal da Bahia), mestra em Psicologia (Universidade Federal Fluminense). É doutoranda em Difusão do Conhecimento pela Universidade Federal da Bahia. Tem experiência na área de produção de subjetividades e políticas minoritárias, com pesquisa nos temas de corpo, somática e dança. Bolsista da Coordenação de Aperfeiçoamento de Pessoal de Nível Superior (CAPES).

E-mail: nayaralongo@yahoo.com.br. 